\title{
Trust of second-generation immigrants: intergenerational transmission or cultural assimilation?
}

\author{
Julie Moschion ${ }^{1,2^{*}}$ and Domenico Tabasso $3,4,5$
}

\author{
* Correspondence: \\ moschion@unimelb.edu.au \\ ${ }^{1}$ Melbourne Institute of Applied \\ Economic and Social Research, The \\ University of Melbourne, 1-100 \\ Grattan Street, Parkville, VIC 3010, \\ Australia \\ ${ }^{2}$ Université Paris-Ouest Nanterre, \\ Nanterre, Cedex 92001, France \\ Full list of author information is \\ available at the end of the article
}

\begin{abstract}
This paper studies the respective influences of intergenerational transmission and the environment in shaping individual trust. Focusing on second generation immigrants in Australia and the United States, we exploit the variation in the home country and in the host country to separate the effect of cultural transmission from that of the social and economic conditions on individual trust. Our results indicate that trust in the home country contributes to the trust of second generation immigrants in both of the host countries, and marginally more in the United States. Social and economic conditions in the host country also affect individual trust.
\end{abstract}

JEL classification: J15, O15, Z10

Keywords: Trust; Migration; Culture

\section{Introduction}

Theoretical and empirical research in economics has shown that trust has important macroeconomic and microeconomic implications. Early research emphasised the importance of trust in the development of market economies (Arrow 1972; Williamson 1979), since it facilitates cooperation and exchanges among anonymous individuals. More recently, empirical research on the impact of trust has identified large positive causal effects on countries' economic performance (growth; income; employment; financial development; and entrepreneurship $)^{1}$. At the individual level trust is associated with positive outcomes such as happiness and economic success (Delhey and Newton 2003). Therefore, differences in trust between countries or between individuals partly explain differences in their respective outcomes.

Investigating the origins of trust is thus relevant to identify further why outcomes between countries or between individuals differ. The theoretical literature emphasises the roles of inherited traits and of the current environment in shaping social attitudes (Bisin and Verdier 2001). Empirically there is evidence that intergenerational transmission on the one hand (Algan and Cahuc 2010; Dohmen et al. 2012) and the environment on the other hand (Leigh 2006; Rothstein and Uslaner 2005) matter for trust. In addition, the relative importance of intergenerational transmission and the environment appears to vary across countries. Specifically, while trust in the home country affects the trust of even third- generation immigrants in the United States (Tabellini 2008), for 
immigrants to Europe, trust in the home country has an effect up to the second generation only (Ljunge 2012). This suggests that in Europe acculturation with natives may be more important. However, there are only few empirical studies which investigate these two channels simultaneously (Algan et al. 2011; Luttmer and Singhal 2011; Dinesen 2011; 2012b). To understand the origins of trust, it is important to identify separately the contribution of cultural transmission and the environment since they could complement or substitute each other.

This paper investigates the respective importance of cultural transmission ${ }^{2}$ and the environment in shaping individual trust of second-generation immigrants in two different countries: Australia and United States. By looking at second-generation immigrants, we aim to isolate the effect of culture from environmental conditions. The results are therefore informative of the extent to which immigrants adapt to natives' culture in the two host countries. Comparing the United States and Australia is of particular interest since these two countries share a number of features in terms of immigration and socio-economic characteristics while exhibiting different average levels of trust, as shown in the descriptive and empirical analyses.

The focus on two different countries allows us to investigate how the assimilation of second-generation immigrants differ between the US and Australia. To reach this aim, we consider the following questions: Is the transmission of trust from home countries different for immigrants to the United States and Australia? Does the level of trust of second-generation immigrants differ between the United States and Australia? If so, do characteristics of the host countries explain these differences? Else, do characteristics of immigrants explain such differences?

Our first contribution is to expand on the literature that focused on trust of migrants in European host countries (Dinesen 2011, 2012b) and assessed the respective importance of home-country culture and the host-country environment on trust of secondgeneration immigrants. In this respect, we bring together two distinct literatures: the one on cultural transmission and that on the effect of social and economic characteristics on trust. To identify the effect of culture, we estimate how the trust of secondgeneration immigrants varies with trust in their home countries. After we control for individual and home-country characteristics, the effect of the environment is then given by unexplained differences in trust levels across the two host countries.

The second contribution of this paper is the investigation of which characteristics of the environment influence the trust of second-generation immigrants. We examine whether the difference in the levels of trust of immigrants between the United States and Australia can be explained by a large set of social and economic characteristics: crime rate; segregation; perceived racial inequality; income inequality; unemployment rate; GDP growth; density of population; and female labour force participation. This is of interest because trust is associated with many economic and social characteristics which can provide potential explanations for differences in trust across countries. These economic and social characteristics may contribute to homogenise trust levels within a country and foster cultural assimilation of immigrants. However, just a few of these explanations have been tested with respect to immigrants' trust levels, and for European countries only (Dinesen 2011).

Third, we contribute to the understanding of why the transmission of trust across generations varies by host country. In this respect, we extend our analysis of the relationship 
between individual trust and trust in the home country to first-generation immigrants. If the effect of trust in the home country on individual trust differs for first-generation immigrants in the United States and Australia, this suggests that the migration choices to one of these two host countries may also differ, reflecting an effect of selection in relation to trust. In contrast, if the effect of trust in the home country on the trust of firstgeneration immigrants is similar for the United States and Australia, this suggests that it is the intergenerational transmission process which drives the differences in the trust of immigrants between the two host countries, not the migration choice per se.

Our results clearly indicate that both the home country and the host country matter to trust. Cultural transmission of trust from the home country is important in explaining trust levels in the United States, and somewhat less important in Australia. Further, differences in the trust of second-generation immigrants between the two host countries remain largely unexplained even after controlling for individual and home-country factors. This suggests that the characteristics of the host-country's environment matter as well. In particular, while low levels of crime, income inequality, unemployment, and segregation partly account for the high level of trust in Australia, the perception of racial inequality contributes to lower levels of trust in the United States. This result has important policy implications for those assimilation policies that aim to foster trust and the development of a commons sense of identity in a heterogeneous population.

The analysis on first-generation immigrants indicates that for these individuals, the influence of the level of trust in the home country is similar for the United States and Australia. This supports our suggestive evidence that the transmission process is stronger in the United States and that acculturation may generate differences in the trust of immigrants between the United States and Australia.

The paper is structured as follows: after presenting the literature and the empirical strategy in the next section, the third section describes the datasets used in the analysis; the fourth section gives some graphical and descriptive evidence on the relationships of interest. The empirical analysis is developed in sections 5 to 7 . Section 8 concludes and presents some indications for future research.

\section{Related literature and empirical strategy}

\subsection{Related literature}

The empirical research on trust gained importance after trust questions were introduced into national and cross-country surveys in the 1980s. Early literature shows a positive relationship between trust and a number of economic outcomes: government effectiveness (La Porta et al. 1997); income per capita; and education (Knack and Keefer 1997). More recently, the literature has begun to investigate the causal mechanisms that link trust to economic outcomes. Several papers use historical values of variables such as religion or political institutions to explain the variation in trust levels across different countries. This research finds that trust influences per capita income (Tabellini 2010) and the probability of becoming an entrepreneur (Guiso et al. 2006). Another strand of the literature uses differences in the trust levels of migrants from different countries or regions as a proxy for exogenous differences in past levels of trust in their country or region of origin. This literature established that trust has a significant impact on growth (Algan and Cahuc 2010; Horváth 2013), financial development (Guiso et al., 2004), employment (Algan and Cahuc, 2007a), and macroeconomic stability (Sangnier, 2013). 
As trust influences economic outcomes, understanding the origins of trust becomes a crucial economic question. So far, some contributions have shown that trust is transmitted across generations. Dohmen et al. (2012) provide credible evidence of a strong-although not causal-link between parents' and children's levels of trust in Germany. Similarly, Algan and Cahuc (2010) exploit the fact that trust levels of US immigrants vary by home country and show that individual trust is partly transmitted from previous generations. For Europe, Ljunge (2012) also finds that the trust of second-generation immigrants depends on trust in their home country. However, other contributions indicate that the local environment is crucial in determining individual level of trust. For example, Rothstein and Uslaner 2005; Leigh 2006; Algan and Cahuc 2007b; and Aghion et al. 2010 show that trust levels vary depending on local, social and economic conditions.

The empirical literature includes only a few studies that analyse the simultaneous influence of culture and of the environment on trust and assess their respective contributions. This is surprising, since the theoretical literature has shown that these different channels interact with each other (Bisin and Verdier 2001). Dinesen and Hooghe 2010, Dinesen (2011, 2012a, 2012b) investigated the effects of both the intergenerational transmission of trust and of the environment in a series of papers based on data from several European countries. Their findings indicate that both channels affect trust although in some cases the role of the environment seems more relevant than that of the intergenerational transmission. However, the analysis of Dinesen faces several limitations. First, Dinesen mostly focuses on first-generation immigrants. This hinders the possibility to precisely assess the role of the environment, as the trust of these individuals may also be affected by the economic and social conditions of their home country. Second, using cross-country datasets which contain small samples for each country prevents him from identifying the effects for each host country separately. Third, Dinesen's evidence is based on a selected group of immigrants, namely immigrants to European countries only moving from low-trust countries to high-trust countries. Last, in his analysis, Dinesen focuses on a relatively small set of host-country characteristics which can affect trust, namely corruption and the perception of fairness of institutions.

This paper contributes to the literature by estimating how the home country and the host country, respectively, affect the individual trust of second-generation immigrants in the United States and Australia. Our paper is quite close in spirit to Dinesens' contributions, but it departs from them in several, important ways. First, we focus on secondgeneration immigrants. This choice guarantees a more accurate estimation of the impact of the intergenerational transmission of culture and values on individual trust. Indeed, by looking at second-generation immigrants, we reduce the risk that our estimates of this cultural effect are biased by spurious correlations with other characteristics of the home country. Second, using two different datasets for the US and for Australia we are able to identify the effects of home and host country on trust separately for the two countries. This provides further insights into how the links between individual trust and intergenerational transmission of culture and the characteristics of the environment vary by host country. Moreover, our results are more general, as in our analysis we do not restrict the set of home countries to low-trust countries only.

In addition, our paper is the first one to focus on the United States and Australia. The choice of these two countries constitutes a critical element in the analysis of the different factors affecting trust. The United States and Australia have quite similar 
immigration histories and share a number of social and economic characteristics. However, the two countries exhibit very different average levels of individual trust. We investigate the reasons for this difference by expanding the set of country level characteristics proposed by Dinesen to include several indicators for the economic conditions in the two countries, and for social characteristics, such as crime levels, racial inequality and racial segregation.

\subsection{Empirical strategy}

We separate the effect of culture on trust from the effect of the environment by studying second-generation immigrants in the United States and Australia. By looking at immigrants located in two different countries, we exploit the variation in the country of residence to identify the effect of the environment on individual trust. Secondgeneration immigrants come from different countries. This additional source of variation allows us to identify the effect of cultural transmission on individual trust. Specifically, to identify the cultural component, we follow the epidemiological approach which studies the variation in outcomes across different immigrant groups residing in the same country ${ }^{3}$. This method relies on the idea that immigrants living in the same country have different cultures but share a common social and economic environment. The effect of culture is captured by the relationship between the average level of trust in the immigrant's home country and her or his level of trust. Focusing on secondgeneration immigrants rather than first-generation immigrants has several advantages. Since second-generation immigrants have never lived in their home country, the link between their individual trust and the average value of trust in that country should capture the extent to which preferences and beliefs are transmitted from one generation to the next. However, economic and institutional conditions (past or present) in the home country should not influence second-generation immigrants' trust. Focusing on second-generation immigrants also eliminates confounding factors which specifically affect the first generation (ability to speak the host-country language, and the impact of the migration). However, it is possible that effects estimated for second-generation immigrants are underestimated if the influence of home-country's values has attenuated over time.

We estimate the following equation:

$$
\begin{aligned}
& T_{i t o r}=\alpha_{0}+\alpha_{1} T_{o}+\alpha_{2} I_{r} * T_{o}+\alpha_{3} I_{r}+\alpha_{4} X_{o}+\alpha_{5} I_{r} * X_{o} \\
& +\alpha_{6} X_{i t}+\alpha_{7} I_{r} * X_{i t}+\alpha_{8} t_{1980}+\alpha_{9} t_{1990}+\alpha_{10} t_{2005}+\varepsilon_{i t o r}
\end{aligned}
$$

where $T_{i t o r}$ is the trust level of individual $i$ in time $t$ from home country $o$ living in country $r ; T_{o}$ is the trust level in the home country; ${ }^{4} I_{r}$ is a dummy for the host country ( 1 for Australia); $X_{o}$ is a set of characteristics from the home country (GDP growth, GDP per capita, unemployment rate, level of democracy); $X_{i t}$ is a set of individual controls (age, gender, education level, marital status, number of children, labour force status, urban or rural residence, region of residence, and indicators for whether both parents were born abroad in the same or different countries). The coefficients $\alpha_{8}, \alpha_{9}$ and $\alpha_{10}$ refer to three country-specific time fixed effects, discussed in detail below.

The main coefficients of interest are $\alpha_{1}, \alpha_{2}$ and $\alpha_{3}$. They respectively indicate the relationship between the level of trust in the home country and the trust of secondgeneration immigrants for the United States, how this link differs in Australia, and the 
unexplained difference between trust levels in the United States and Australia. $\alpha_{1}+\alpha_{2}$ indicates the intergenerational transmission effect for Australia. If trust is passed down from generation to generation, the level of trust in the home country is expected to be related to individual trust and $\alpha_{1}$ to be positive (as well as $\alpha_{1}+\alpha_{2}$ ). The coefficient of the dummy for the host country, $\alpha_{3}$, indicates the presence of differences in trust between the United States and Australia which are unexplained by other control variables. Thus, the inter-home-country variation gives the effect of culture while the inter-hostcountry variation gives the effect of the environment.

A spurious correlation between individual trust and trust in the home country could arise if the variation in the home country trust does not reflect only culture but also variation in the home country conditions. To pick up possible indirect effects of culture, the econometric framework includes standard individual controls and home-country controls. The coefficients $\alpha_{1}$ and $\alpha_{2}$ may not reflect only variation in home-country trust but also variation in other home country conditions. Therefore home-country characteristics are included to reduce the effects of these conditions on the estimated parameters $\alpha_{1}$ and $\alpha_{2}$. Moreover, these home-country characteristics are included to reduce the impact that differences in the composition of the immigrant population in the two countries can exert on the estimation of the coefficient $\alpha_{3}{ }^{5}$

Including individual controls reduces the potential for spurious correlation affecting the estimation of the host-country dummy if differences in trust levels between the United States and Australia are accounted for by differences in individual characteristics. The individual controls are time-variant while trust in the home country and home-country characteristics are invariant in time. To allow all of the individual and country effects to vary by host country, $I_{r}$ is interacted with all variables.

In addition, we include time controls that are specific to each host country in order to account for differences between our datasets. Specifically, we include decennial dummies for the 1980s and 1990s for the United States (periods which are not included in the Australian data). For Australia, we include a dummy for 2005, a year in which Australian respondents reported surprisingly low levels of trust. As a result, $\alpha_{3}$ gives the unexplained difference in trust levels between the United States in the 2000's and Australia in other years than $2005^{6}$.

In Section 6, we provide further insight into what may drive the difference in trust levels between the United States and Australia (as estimated by $\alpha_{3}$ in equation 1). We test the effect of the following different social and economic characteristics: crime rates; segregation; perceived racial inequality; income inequality; unemployment rate; GDP growth; density of population; and female labour force participation. Coefficients $\alpha_{4}$ and $\alpha_{5}$ show how time variations in these variables correlate with variations in trust. Since changes in these characteristics may take time to exert an effect on trust, we investigate contemporaneous and lagged effects of these variables on trust.

Characteristics of the host country were chosen to test the relationships with trust that are identified in the literature. First, Delhey and Newton (2003) and Uslaner (2002) find a clear negative relationship between trust and people's feelings of safety when walking alone at night. The degree of security that people experience influences their belief about whether most people can be trusted or not. We further test this association at the country level using a more objective measure of safety: crime rates. Second, there is evidence that trust is enhanced through interactions with people of different 
backgrounds (Glaeser 2005), which are possibly more developed in integrated areas than in segregated areas. In contrast, diversity (fractionalisation) does not guarantee residential integration and does not necessarily give opportunities for people from different backgrounds to interact (Uslaner 2011). Uslaner (2008) finds that integration rather than diversity enhances trust. Alesina and Zhuravskaya (2011) further demonstrate (for a crosssection of countries) that segregation causally weakens generalised trust, which in turn lowers the quality of governments. We test whether segregation by country of origin ${ }^{7}$ could account for some of the differences in trust between the United States and Australia.

The literature contains clear evidence of a negative relationship between trust and inequality (Rothstein and Uslaner 2005), and trust and the perception of inequality. In particular, Rothstein and Stolle (2008) argue that individuals' trust is partly determined by the perceived fairness of institutions and their enforcement. The negative effects of corrupted institutions and the lack of civic mindedness of citizens on trust have been clearly established. Similarly, having experienced inequality-for example through discrimination-can weaken an individual's trust (Rothstein and Stolle 2008). This seems particularly relevant in the case of immigrants. We test this using a measure of perceived racial inequality as a proxy. We also assess the influence of an objective measure of income inequality (Gini coefficients), since Uslaner (2002) finds that: "What distinguishes countries that are trusting from those that are not is the level of economic equality'.

Also, we test the effect of other economic conditions, such as unemployment levels and GDP growth. While the literature has not identified a clear effect of contemporaneous economic measures on trust, we test whether this effect can appear with a lag. The host-country characteristics are added to the model and are tested individually, in addition to the baseline model. This is because the degrees of freedom are very limited for Australia, due to the relatively short interval of time covered by the HILDA data. Further, since these variables are highly correlated with each other, we prefer to analyse their effects in separate regressions.

\section{Data}

The individual data used in the analysis for Australia come from the Household, Income and Labour Dynamics in Australia (HILDA) survey, and for the United States from the General Social Survey (GSS). HILDA is a household-based panel study which began in 2001; interviews are conducted annually for all members of the sampled households who are aged 15 years or older. GSS is a US survey which began in 1972. It collects data on a randomly selected sample of individuals aged 18 years or older (Smith et al. 2011). While the GSS is a repeated cross-section which covers a relatively long interval of time, the HILDA survey is a longitudinal dataset with a limited time dimension. The different structures of the two datasets and the differences in the time intervals covered by the two surveys may bias our estimates. In order to assess the relevance of this bias we complement our main results with a wide range of robustness tests ${ }^{8}$. Moreover, in our empirical analysis, we cluster the standard errors at the individual level in all of the regressions to account for the longitudinal feature of HILDA and avoid reducing standard errors artificially. We also include time controls which are specific to the host country to account for the difference in periods covered. For both surveys, we select the waves which include information on trust 
and which enable us to identify the home country of second-generation immigrants: HILDA 2005, 2006, 2008, 2010; and GSS 1978, 1980, 1983, 1984, 1986 to 1991, 1993, and every two years from 1994 to 2010. HILDA and GSS include the following questions on trust:

- HILDA: 'To what extent do you agree or disagree with the following statements? [...] Generally speaking, most people can be trusted.'

Responses are coded between 1 and 7, where 1 indicates that the person strongly disagrees and 7 that he or she strongly agrees.

- GSS: 'Generally speaking, would you say that most people can be trusted or that you can't be too careful in dealing with people?'

Responses are coded between 1 and 3, where 1 stands for 'Can trust', 2 for 'Cannot trust', and 3 for 'Depends'.

Measuring trust through surveys can be problematic. However, previous research, including large-scale field experiments, demonstrated the behavioural validity of these survey instruments; answers actually translate into reciprocal actions (Glaeser et al. 2000, Fehr et al. 2003, Thöni et al. 2012). In order to have comparable measurements of trust in the United States and Australia, we harmonise the coding of this variable by creating a dummy equal to 1 (trusting) if the value in the GSS equals 1 or if the HILDA response is between 5 and 7; and equal to 0 otherwise. We recoded GSS and HILDA trust variables such that the percentages of trusting individuals in the two datasets are as close as possible to those observed in the World Value Survey (WVS) for the United States and Australia.

We define second-generation immigrants as individuals born in Australia or the United States with at least one parent born overseas. HILDA provides us with information on the country of birth of both parents and of the individual. In the GSS, each US-born individual is asked whether either of their parents was born abroad and to specify the country of origin for the family. We identify second-generation immigrants from answers to the first question and the home country from the second question. The home country is defined as the father's country of birth unless only the mother was born overseas, in which case the mother's country of birth is taken as the home country9. We then restrict our analysis to respondents coming from countries for which we have at least 40 individuals. This restriction implies that we keep more than 90 percent of second-generation immigrants in the Australian sample, and more than 80 percent in the US sample.

The values for trust in the home countries are obtained from the WVS (WVS Association 2009). The WVS trust question reads: 'Generally speaking, would you say that most people can be trusted, or that you need to be very careful in dealing with people?' It is coded as a dichotomous variable. The two answers are: 'Most people can be trusted' versus 'Need to be very careful'. From the WVS we select all countries that appear as home countries for our HILDA and GSS samples ${ }^{10}$. The earliest measure of trust in the WVS is from the 1981 wave, but often from a later wave for most countries. Since our sample consists of second-generation immigrants, immigration occurred before the individual was born. Therefore, we would prefer to use average measures of trust recorded before the respondent was born. Unfortunately, 96 per cent of the individuals in our sample were 
born before a second set of values on trust from their home country was recorded in the WVS. As a result, for this substantial majority the best proxy for trust in their home country at the time of immigration is the first value available in the $\mathrm{WVS}^{11}$.

Additional file 1: Table 7 provides the final list of home countries and the distribution of observations for each country in the two datasets. In total, we observe individuals coming from 27 different countries, with 14 countries for the United States and 21 countries for Australia. Eight home countries appear in both the Australian and US samples.

The GSS and the HILDA surveys include the following individual characteristics which we employ in the set of controls: the individual's gender; age; education level; labour force status; marital status; number of children; region of residence; and density of the town of residence. Wherever the coding of these variables differed between the GSS and HILDA, it was harmonised (see Additional file 2: Table 8 for details). Table 1 includes summary statistics of the control variables after the harmonization between the two datasets. Home-country characteristics (GDP growth; GDP per capita; unemployment rate; index of democracy) are obtained from the Organization of Economic Cooperation and Development (OECD), the International Labour Office (ILO), and the Freedom House databases. For consistency we include the values of these variables taken at the same date as the trust variable. For example, an Italian immigrant surveyed in Australia in 2005 is allocated the values of the Italian variables observed in 1981 (the first year in which the WVS interviews were conducted in Italy).

The variables summarising the host-country environment are: crime rate; segregation; perceived inequality; income inequality; unemployment rate; GDP growth; density of population; and female labour force participation ${ }^{12}$. They are sourced from the US Bureau of Statistics, the US Census Bureau, the US Department of Justice, the Australian Bureau of Statistics, the World Bank, the OECD, the Luxembourg Income Study, and the International Social Survey Programme (ISSP) on social inequalities. In particular, we use the ISSP question on whether one thinks that 'race is important to get ahead' in order to build a measure of perceived racial inequality in the host country ${ }^{13}$. We test different versions of these variables: contemporaneous to GSS and HILDA waves and with one to 13-year lags (using three-year moving averages) ${ }^{14}$. For example, for an Italian immigrant surveyed in Australia in 2005, we test using the 2005 values of the Australian variables and all the lagged values from 2004 back to 1992.

\section{Descriptive analysis}

Table 1 describes our sample of second-generation immigrants in the United States and Australia. On average, US individuals are older and have a slightly greater number of children than Australians. Given the older sample, the observations from the United States include more widowed or separated individuals and more respondents who are out of the labour force. Most importantly, second-generation immigrants to the two countries differ in their level of trust: while 61 per cent of Australian second-generation immigrants believe that most people can be trusted, only 41 per cent of the US second-generation immigrants believe this. Interestingly, these levels of trust are very close to those of the general population which are respectively 60 per cent in Australia and 39 per cent in the United States $^{15}$. In terms of country characteristics, the United States and Australia also show some large differences in terms of population density and crime rate. However, second- 
Table 1 Descriptive statistics

\begin{tabular}{|c|c|c|c|c|c|c|c|c|}
\hline & \multicolumn{4}{|c|}{ US } & \multicolumn{4}{|c|}{ AUSTRALIA } \\
\hline & Mean & $\begin{array}{r}\text { Std } \\
\text { Deviat }\end{array}$ & Min & $\operatorname{Max}$ & Mean & $\begin{array}{r}\text { Std } \\
\text { Deviat }\end{array}$ & Min & Max \\
\hline Trust in the host country & 0.406 & 0.491 & 0 & 1 & 0.609 & 0.488 & 0 & 1 \\
\hline Trust in the home country & 0.329 & 0.118 & 0.06 & 0.609 & 0.387 & 0.089 & 0.055 & 0.491 \\
\hline \multicolumn{9}{|l|}{ Individual statistics } \\
\hline Proportion of males & 0.446 & 0.497 & 0 & 1 & 0.475 & 0.499 & 0 & 1 \\
\hline Age & 54.32 & 19.55 & 18 & 89 & 41.04 & 18.22 & 15 & 93 \\
\hline Less than high school & 0.264 & 0.441 & 0 & 1 & 0.326 & 0.468 & 0 & 1 \\
\hline High school & 0.491 & 0.500 & 0 & 1 & 0.183 & 0.387 & 0 & 1 \\
\hline College & 0.045 & 0.208 & 0 & 1 & 0.284 & 0.451 & 0 & 1 \\
\hline Bachelor & 0.128 & 0.334 & 0 & 1 & 0.122 & 0.327 & 0 & 1 \\
\hline Postgraduate & 0.073 & 0.259 & 0 & 1 & 0.084 & 0.277 & 0 & 1 \\
\hline Married & 0.509 & 0.500 & 0 & 1 & 0.589 & 0.492 & 0 & 1 \\
\hline Widowed & 0.184 & 0.388 & 0 & 1 & 0.045 & 0.208 & 0 & 1 \\
\hline Separated & 0.115 & 0.319 & 0 & 1 & 0.057 & 0.232 & 0 & 1 \\
\hline Divorced & 0.020 & 0.142 & 0 & 1 & 0.025 & 0.155 & 0 & 1 \\
\hline Never married & 0.171 & 0.377 & 0 & 1 & 0.283 & 0.450 & 0 & 1 \\
\hline Employed full-time & 0.382 & 0.486 & 0 & 1 & 0.441 & 0.496 & 0 & 1 \\
\hline Employed part-time & 0.088 & 0.283 & 0 & 1 & 0.230 & 0.421 & 0 & 1 \\
\hline Unemployed & 0.052 & 0.221 & 0 & 1 & 0.036 & 0.185 & 0 & 1 \\
\hline Out of the labour force & 0.478 & 0.499 & 0 & 1 & 0.294 & 0.455 & 0 & 1 \\
\hline One parent is immigrant & 0.496 & 0.500 & 0 & 1 & 0.662 & 0.473 & 0 & 1 \\
\hline $\begin{array}{l}\text { Both parents are immigrants, different } \\
\text { origins }\end{array}$ & 0.392 & 0.488 & 0 & 1 & 0.083 & 0.277 & 0 & 1 \\
\hline $\begin{array}{l}\text { Both parents are immigrants, same } \\
\text { origin }\end{array}$ & 0.099 & 0.299 & 0 & 1 & 0.254 & 0.435 & 0 & 1 \\
\hline Number of children & 2.077 & 1.819 & 0 & 8 & 1.500 & 1.566 & 0 & 8 \\
\hline Major urban areas & 0.511 & 0.500 & 0 & 1 & 0.649 & 0.478 & 0 & 1 \\
\hline Other urban areas & 0.303 & 0.459 & 0 & 1 & 0.208 & 0.406 & 0 & 1 \\
\hline Bounded localities & 0.094 & 0.291 & 0 & 1 & 0.024 & 0.153 & 0 & 1 \\
\hline Rural areas & 0.092 & 0.289 & 0 & 1 & 0.119 & 0.324 & 0 & 1 \\
\hline \multicolumn{9}{|l|}{ Host-country statistics } \\
\hline GDP growth & 3.290 & 1.877 & -3.369 & 7.186 & 3.015 & 0.561 & 2.257 & 3.832 \\
\hline Unemployment rate & 6.100 & 1.400 & 4.000 & 9.600 & 4.846 & 0.359 & 4.279 & 5.237 \\
\hline Female labour force participation & 56.71 & 3.162 & 50.00 & 59.90 & 57.99 & 0.729 & 56.99 & 58.74 \\
\hline Population density & 28.20 & 2.793 & 24.25 & 33.77 & 2.745 & 0.085 & 2.648 & 2.865 \\
\hline Crime rate & 7.764 & 1.630 & 4.80 & 10.20 & 2.491 & 0.312 & 2.000 & 2.800 \\
\hline Gini index & 0.351 & 0.016 & 0.328 & 0.380 & 0.322 & 0.010 & 0.310 & 0.336 \\
\hline Segregation index & 0.084 & 0.013 & 0.060 & 0.103 & 0.001 & 0.000 & 0.001 & 0.001 \\
\hline Perceived racial inequality & 0.389 & 0.039 & 0.303 & 0.423 & 0.257 & 0.026 & 0.225 & 0.289 \\
\hline \multicolumn{9}{|l|}{ Home-country statistics } \\
\hline GDP growth & 1.871 & 4.578 & -11.6 & 8.8 & 0.617 & 2.749 & -2.90 & 7.80 \\
\hline Unemployment rate & 6.897 & 3.396 & 1.50 & 13.7 & 9.495 & 2.494 & 1.50 & 13.20 \\
\hline
\end{tabular}


Table 1 Descriptive statistics (Continued)

\begin{tabular}{lrrrrrrrr}
\hline Female labour force participation & 42.71 & 10.25 & 29.7 & 63 & 40.34 & 8.822 & 20.20 & 70.00 \\
Democracy levels & 1.808 & 1.406 & 1 & 6 & 1.742 & 1.705 & 1 & 7 \\
\hline
\end{tabular}

Sample: second-generation immigrants residing in the United States or in Australia.

Source: HILDA 2005, 2006, 2008, 2010 and GSS 1978-2010. Sources for country statistics: World Bank, OECD, ILO,

Freedom House, US Census Bureau, ABS, US Department of Justice.

generation immigrants to the United States and Australia come from countries which are quite similar in terms of trust levels: the average trust level in the countries of origin is 33 per cent for the US sample and 39 per cent for the Australian one.

Figure 1 shows the evolution of trust levels in the United States and Australia for three subgroups of the population: non-immigrants, first-generation immigrants and second-generation immigrants. Trust is consistently higher in Australia for all three groups. In both countries, second-generation immigrants have levels of trust which are very close to those of non-immigrants, while those of first-generation immigrants are systematically lower than for the rest of the population. The evolution of trust in Australia is also very similar for immigrants and non-immigrants. By contrast, in the United States the dynamics of trust are not so similar across groups. This is confirmed when looking at the evolution of trust over time by home country for the two host countries: ${ }^{16}$ trust levels of second-generation immigrants evolve much more heterogeneously in the United States than in Australia. This suggests that the effect of the environment on trust may be larger in Australia than in the United States.

Figure 2 shows the relationship between the average level of trust of second-generation immigrants in the United States and Australia and the average trust in their home country. Many home countries show consistently low or high levels of trust in both host countries. Immigrants from Ireland and Great Britain display high levels of trust, while immigrants from Canada and Hungary display medium levels and Italians report low values. This indicates that the level of trust in a home country may affect the trust of second-generation immigrants. Note that some other home countries rank very differently for the United States and Australia (Austria, Poland and Germany). These discrepancies could be due to different waves of immigration, especially whether the immigration took place before or after the Second World War, and before or after the fall of the Communist regimes.

Finally, Figure 2 shows that trust of second-generation immigrants is highly and positively correlated with trust in their home country in both the United States and Australia. The correlation coefficients are 0.83 in the United States and 0.6 in Australia.

\section{Individual trust: between intergenerational transmission and cultural assimilation}

This section explores whether (i) the link between trust levels of second-generation immigrants and trust in their home country is confirmed when analysed in a more complete framework; and (ii), whether the difference in the trust levels of US and Australian immigrants can be explained by individual and home-country characteristics.

\subsection{Results}

Table 2 presents the results from regressions of individual trust of second-generation immigrants on trust in their home country, as specified in equation (1). We show three 


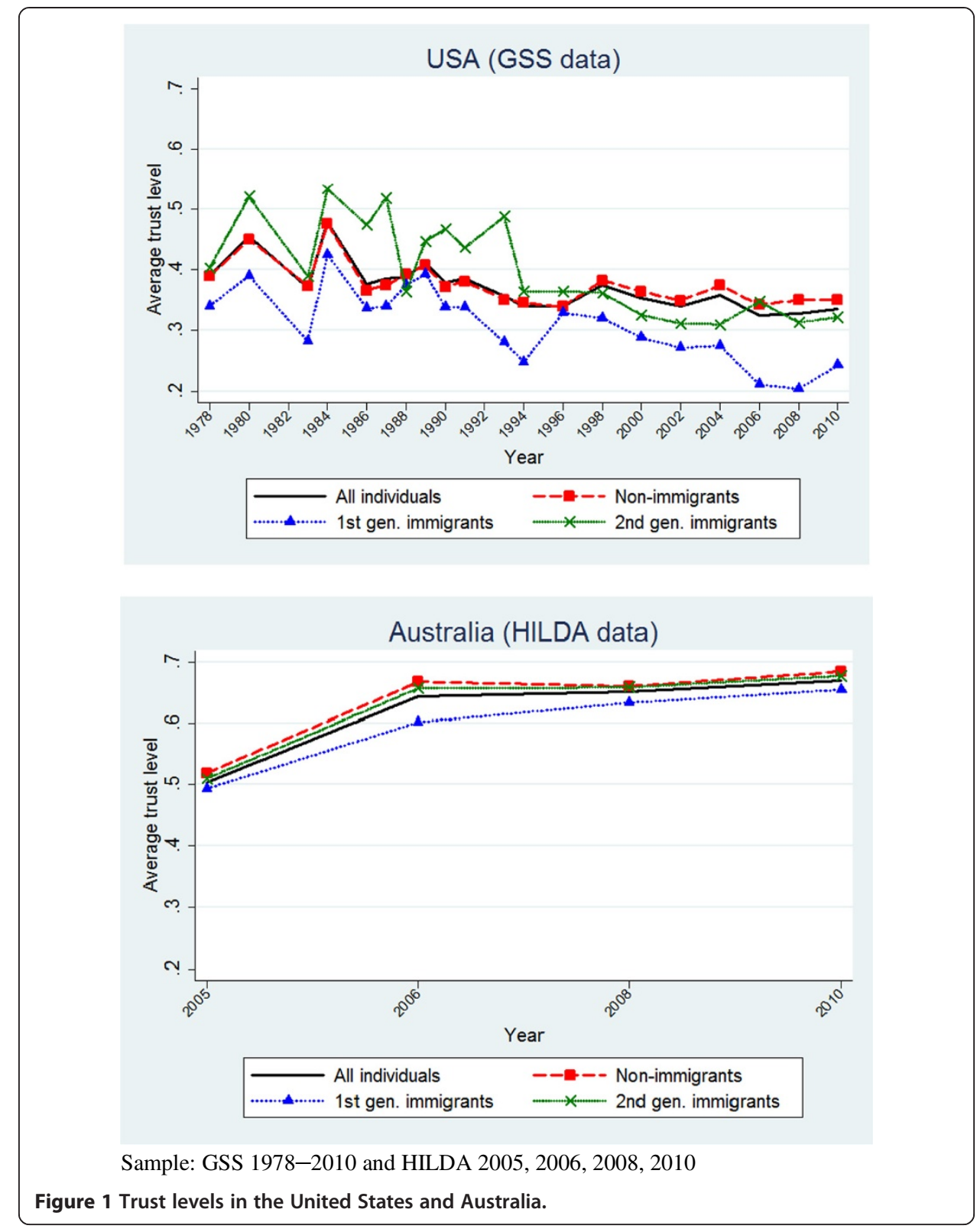

specifications which include an increasing number of controls at the individual and home-country level. Table 2 reports the coefficients related to: trust in the home country (for the United States and the difference for Australia); the indicator for the host country; and the home-country characteristics (the complete set of results can be found in Additional file 3: Table 9). All three specifications control for age and time fixed effects to account for these essential differences between the US and Australian data.

The first column of Table 2 indicates that the trust level of second-generation immigrants in both host countries is significantly correlated with trust in their home country, but the link is much stronger in the United States. A 10 percentage point shift in trust in the home country implies a 7.1 percentage point increase in the probability that US second-generation immigrants are trusting. Conversely, the comparable increase is only 1.7 percentage points in Australia (5.4 percentage points lower) ${ }^{17}$. In line with the 


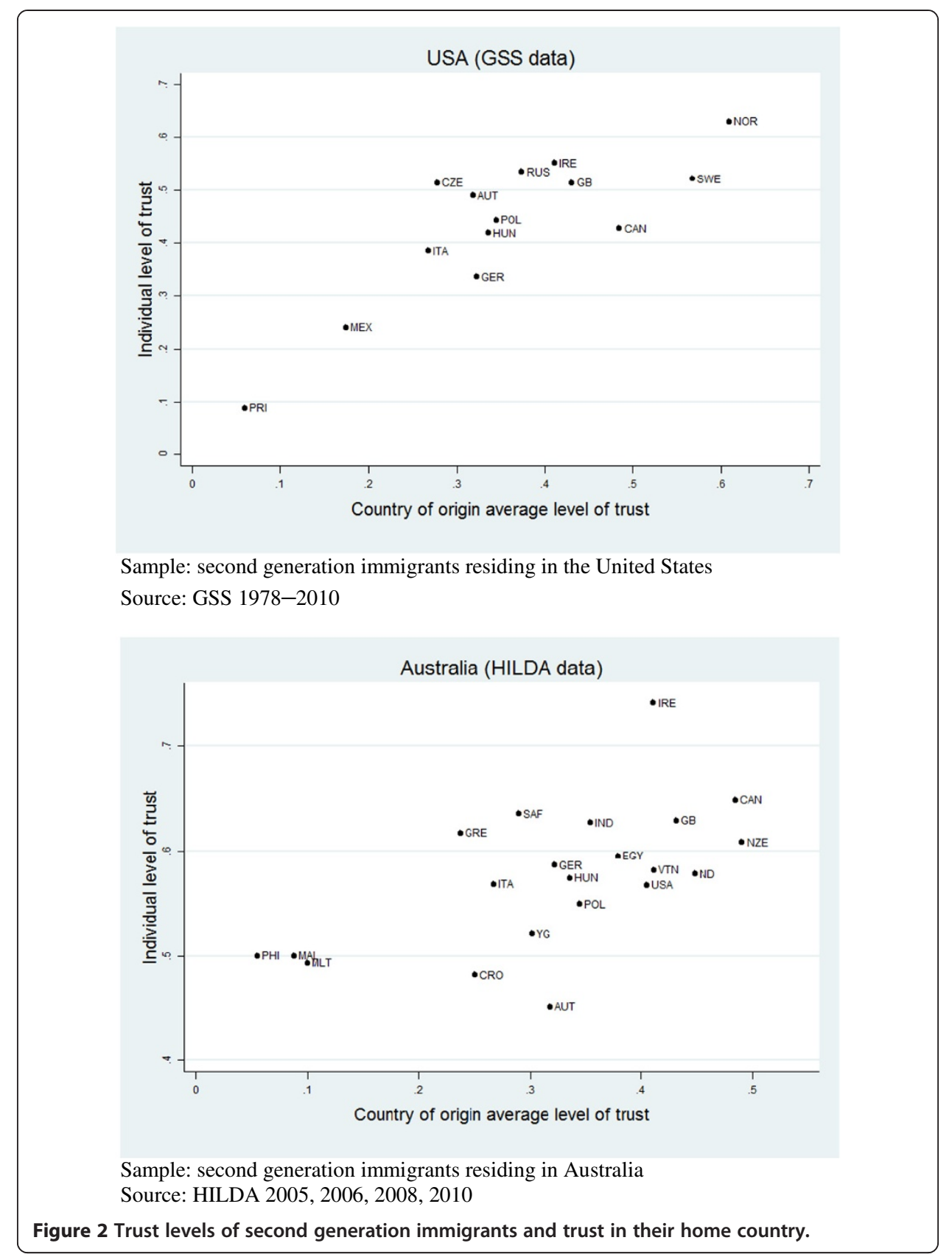

descriptive statistics, the results indicate also a large difference in the level of trust between the United States and Australia: the probability of trusting other people is more than 60 percentage points higher in Australia than in the United States.

Although these results suggest a direct transmission of trust from one generation to the next, they may actually derive from the transmission of other characteristics related to trust. If, for example, education patterns are transmitted across generations and correlated with trust levels, the results from the first column would capture the effect of education on trust. To test whether the intergenerational transmission of trust affects individual trust beyond its influence on other individual dimensions, we introduce a number of controls for individual characteristics (column 2). The inclusion of these controls 
Table 2 OLS regressions

\begin{tabular}{lccc}
\hline & $\mathbf{( 1 )}$ & $\mathbf{( 2 )}$ & $\mathbf{( 3 )}$ \\
\hline Trust in the home country & $0.708^{* * *}$ & $0.411^{* * *}$ & $0.568^{* * *}$ \\
Australia X trust in the home country & $(0.094)$ & $(0.107)$ & $(0.125)$ \\
& $-0.539^{* * *}$ & -0.167 & $-0.290^{*}$ \\
Country: $0=$ US, 1 = Australia & $(0.125)$ & $(0.136)$ & $(0.158)$ \\
& $0.604^{* * *}$ & $0.728^{* * *}$ & $0.652^{* * *}$ \\
R-squared & $(0.092)$ & $(0.133)$ & $(0.172)$ \\
Observations & 0.084 & 0.118 & 0.120 \\
Time fixed effects & 9,954 & 9,954 & 9,954 \\
Age and age squared & Yes & Yes & Yes \\
Other individual controls & Yes & Yes & Yes \\
Home-country characteristics & No & Yes & Yes \\
\hline
\end{tabular}

Levels of significance: *: $10 \% * *: 5 \% * * * 1 \%$

Sample: second-generation immigrants residing in the United States or in Australia.

Note: standard errors (clustered at the individual level) in parentheses. The additional individual controls are: gender, education levels, marital status, number of children, labour force status, urban or rural residence, region of residence, an indicator for whether both parents are immigrants from different countries, and an indicator for whether they are from the same country. Home-country characteristics are GDP growth, GDP per capita, unemployment rate, and democracy level. Controls are also interacted with an indicator for Australia.

Source: HILDA 2005, 2006, 2008, 2010 and GSS 1978-2010.

Dependent variable: Most people can be trusted (0: No; 1: Yes).

weakens the link between trust in the home country and individual trust in the United States. In contrast, the relationship with trust in the home country increases in Australia (the difference between the United States and Australia is now smaller). However, the relationship is still clearly positive and significant for both countries and is larger in the United States, although the difference with Australia is not statistically significant. A 10 percentage point increase in average trust in the home country still increases the probability of trusting other people by 4.1 percentage points in the United States and 2.4 percentage points in Australia. Moreover, even after the inclusion of individual controls the difference in the level of trust between the United States and Australia remains large (on average individual trust is 73 percentage points higher in Australia).

Interestingly, most of the significant relationships between trust and individual characteristics differ between the United States and Australia (Additional file 3: Table 9). First, while trust increases with age in the United States, it does not seem to vary with age in Australia. Neglecting to control for age could therefore create a spurious correlation between trust in the home country and trust in the United States. In fact, older individuals (who are more trusting) also happen to come from countries with higher levels of trust ${ }^{18}$.

Second, while in the United States men are slightly more trusting than women, this is not the case in Australia. The lack of clear relationships between age and trust and between gender and trust in Australia is in line with what was observed by Leigh (2006).

Third, the level of education is very positively and consistently related to trust in the United States. The direction of causality could go either way: undertaking more education could increase trust; being more trusting could lead individuals to seek more education. In Australia, even if the level of education is positively related to trust overall, the link with trust is much weaker than in the United States. 
Finally, trust and unemployment do not seem to be related in the United States. On the contrary, in Australia unemployed respondents have a lower trust level than do those who are employed full-time.

As already discussed in presenting the empirical strategy, heterogeneity in economic conditions across the different home countries may bias our estimates. To explore whether the differences in trust by home country are driven by economic conditions in the home country, we add the following controls to our regressions: GDP growth, GDP per capita, unemployment and democracy. The results remain fairly stable (Table 2, column 3): trust in the home country is still positively related to individual trust, and slightly more so in the United States. This suggests that trust is transmitted across generations, beyond the transmission of circumstances, in both the United States and Australia. Once individual and home-country controls are introduced, the difference in the extent of intergenerational cultural transmission between the United States and Australia, summarised by the coefficient $\alpha_{2}$, is statistically insignificant or weakly significant. Therefore, any interpretation of this difference must take into account its relative statistical fragility. However, it is also worth noting that the magnitude of the estimated effect is not negligible, implying at least a difference of around 2 percentage points in the effect of trust in the home country between the US and Australia.

Overall, the results presented in Table 2 leads to two main conclusions:

1) Second-generation immigrants' trust is positively related to trust in their home country. This relationship is slightly stronger in the United States than in Australia.

2) The difference between the trust levels of US and Australian immigrants remains largely unexplained by individual and home-country characteristics.

\subsection{Robustness checks}

Our main objective is to analyse the differences in the trust of second-generation immigrants in the United States and Australia. Therefore, our main unit of analysis are host and home countries. However, characteristics of the region of residence may have an effect on our estimates. Some spurious correlations between trust in the home country and individual trust could arise if immigrants were sorting themselves into locations in a way that is related to trust in their home country, and if the local conditions in the host country, in turn, affect individual trust. To control for these effects, we replicate our analysis including controls for characteristics of the region of residence (GDP growth, unemployment rate, density of population, crime rate). The results are presented in the first column of Table 3. Controlling for regional time-varying characteristics does not change the results; a 10 percentage point increase in average trust in the home country still increases the probability of trusting other people by 5.4 percentage points in the United States and 3.3 percentage points in Australia. As before, the differential effect for Australia is not statistically significant, but relevant in magnitude (2.1 percentage points). The difference between the level of trust in the United States and in Australia decreases, but it remains large with a probability of trusting other people which is 45 percentage points higher in the latter than in the former ${ }^{19}$.

The GSS and HILDA datasets differ in terms of coverage and structure. We run different tests to account for these differences and we check the stability of our results. 
With respect to the coverage, our US and Australian samples vary along two characteristics: the countries of origin of the sample members and the periods covered by the surveys. We test the robustness of our results to these two differences (Table 3). We start by running the same regression as in Table 2 column 3, but only on the eight countries that are common to the United States and Australia (column 2). We find results which are qualitatively similar to those presented in Table 2: the effect of trust in the home country is higher for the United States and the difference compared with Australia is still large, although not statistically significant. This finding rules out the possibility that the results in Table 2 are driven by the presence in one of the two surveys of immigrants whose cultural links to their home country are particularly intense or particularly weak. In addition, the difference between trust levels in the United States and Australia is greater when we restrict the sample to common countries (1.415). This further suggests that the host-country environment may be closely linked to individual trust of second generation-immigrants.

The second element of differentiation between the samples which we control for is that immigrants of British origin represent around 50 per cent of the Australian sample against 11 per cent of the US sample (Additional file 1: Table 7). After dropping second-generation immigrants from the United Kingdom (Table 3, column 3), estimates are extremely similar to those we presented in Table 2. Therefore, the lower effects that we estimate for Australia than for the United States cannot be attributed to the immigrants from the United Kingdom having a particularly weak link to their home country $^{20}$.

To account for differences in the period covered by the two datasets, we repeated our main regression using the GSS only for the period 2002-10 (column 4). Again, the results from the previous section are confirmed. The difference in the effect of trust in the home country between the United States and Australia is even larger $(-0.375)$, although not statistically significant. Finally, we account for the fact that the levels of trust reported in the 2005 wave of HILDA appear to be systematically lower than those reported in the other waves. There is no clear reason for these lower values. In the last

Table 3 Robustness checks, differences in home countries and time periods

\begin{tabular}{|c|c|c|c|c|c|}
\hline & $\begin{array}{l}\text { With regional } \\
\text { characteristics }\end{array}$ & $\begin{array}{l}\text { Common } \\
\text { countries }\end{array}$ & $\begin{array}{c}\text { Excluding } \\
\text { GB }\end{array}$ & $\begin{array}{c}\text { Common } \\
\text { period }\end{array}$ & $\begin{array}{c}\text { Excluding } \\
2005\end{array}$ \\
\hline \multirow[t]{2}{*}{ Trust in the home country } & $0.540^{* * *}$ & $1.184^{* *}$ & $0.568^{* * *}$ & $0.656^{* * *}$ & $0.568^{* * *}$ \\
\hline & $(0.125)$ & $(0.469)$ & $(0.125)$ & $(0.241)$ & $(0.125)$ \\
\hline \multirow{2}{*}{$\begin{array}{l}\text { Australia } X \text { trust in the } \\
\text { home country }\end{array}$} & -0.206 & -0.554 & $-0.285^{*}$ & -0.375 & $-0.291^{*}$ \\
\hline & $(0.164)$ & $(0.773)$ & $(0.162)$ & $(0.260)$ & $(0.164)$ \\
\hline \multirow{2}{*}{$\begin{array}{l}\text { Country: } 0=U S, 1= \\
\text { Australia }\end{array}$} & $0.450^{*}$ & $1.415^{* * *}$ & $0.709^{* * *}$ & $0.572^{* *}$ & $0.640^{* * *}$ \\
\hline & $(0.254)$ & $(0.548)$ & (0.189) & $(0.279)$ & $(0.175)$ \\
\hline R-squared & 0.120 & 0.112 & 0.127 & 0.092 & 0.119 \\
\hline Observations & 9,954 & 7,122 & 5,901 & 8,514 & 7,994 \\
\hline
\end{tabular}

Levels of significance: *: $10 \%{ }^{* *}: 5 \%{ }^{* * *}: 1 \%$.

Sample: second-generation immigrants residing in the United States or in Australia.

Note: standard errors (clustered at the individual level) in parentheses. Region of residence characteristics are GDP

growth, unemployment rate, population density, crime rate, and the percentage of immigrants from the respondent's

home country in the host country (these are time-variant). The additional controls are as in Table 2, column 3.

Source: HILDA 2005, 2006, 2008, 2010 and GSS 1978-2010.

Dependent variable: Most people can be trusted (0: No; 1: Yes). 
column of Table 3, we report the results obtained when dropping the 2005 data. Once again, previous results are confirmed.

The two datasets also differ in terms of their structure, with GSS being a repeated cross-section survey and HILDA being a panel survey. In order to evaluate how these differences impact on our estimates, we assess the sensitivity of the results to two different treatments of the panel dimension (Additional file 4: Table 10): the estimation of a random effects model (column 2); and the selection of the first observation for each individual in the HILDA sample (which corresponds to the observation recorded 2005 in 80 per cent of cases; column 3$)^{21}$. In both cases results are not significantly different from those in Table 2. If anything, the change in the point estimates provide even stronger evidence that the effect of one's home country is smaller in Australia than in the United States. Keeping the first observation in the HILDA also yields standard errors which are very similar to those obtained in the previous section: this suggests that keeping all the observations and clustering standard errors at the individual level does not artificially reduce the standard errors.

As an additional test to validate the results presented in Table 2, we repeat the analysis using a probit specification instead of linear regressions. Once again the results are in line with those presented in Table 2 (column 4).

Finally, we also test how changes in our measure of trust in the home country affect our results (Additional file 5: Table 11). Using the average of trust across all available waves in the WVS-instead of the first wave only-yields identical results. Results are also very similar if we use the mothers' country of birth instead of the fathers' to define the home country. If anything, the effect of trust in the home country appears even smaller in Australia (-0.328).

\subsection{Individual heterogeneity}

This section analyses whether the differences in trust levels of second-generation immigrants and in the intergenerational transmission of trust vary across different segments of the population. In particular, we focus on differences by: gender, age, number of foreign parents, and the relative size of the home-country community in the host country. Table 4 reports the results based on our main specification.

In each column, the statistical significance of the variables interacted with 'subgroup' indicates the strength of the difference in the effect between the 'subgroup' and the reference groups (females; individuals older than 45 years; individuals with only one parent who migrated to the host country; and individuals who belong to small migrant communities). In the United States (first and fourth coefficients in all columns), individual trust of men and women is similarly influenced by trust in their home country (the estimated effects are 0.669 and 0.511 respectively). Interestingly, this is not the case for second-generation immigrants in Australia, where only men's trust is positively related to trust in the home country ( 0.562 and -0.003 respectively). As a result, while the difference in the impact of trust in the home country between the United States and Australia is very large for women $(-0.514)$, it is small for men $(-0.107)$. This could suggest that in Australia women adapt much faster to their environment than men.

Since all of the individuals in our sample were born in the United States or in Australia, it may be expected that the older they become, the lower is the influence of 
Table 4 OLS regressions on subsamples

\begin{tabular}{|c|c|c|c|c|}
\hline & $\begin{array}{c}\text { Female/male } \\
\text { individuals }\end{array}$ & $\begin{array}{l}\text { Young/old } \\
\text { individuals }\end{array}$ & $\begin{array}{c}\text { One/two parent(s) } \\
\text { born abroad }\end{array}$ & $\begin{array}{c}\text { Small/large } \\
\text { communities }\end{array}$ \\
\hline \multirow[t]{2}{*}{ Trust in the home country } & $0.511^{* * *}$ & $0.504^{* *}$ & $0.701^{* * *}$ & 0.028 \\
\hline & $(0.169)$ & $(0.215)$ & $(0.172)$ & $(0.227)$ \\
\hline \multirow{2}{*}{$\begin{array}{l}\text { Australia } X \text { trust in the home } \\
\text { country }\end{array}$} & $-0.514^{* *}$ & -0.277 & $-0.368^{*}$ & 0.399 \\
\hline & $(0.220)$ & $(0.242)$ & $(0.223)$ & $(0.267)$ \\
\hline \multirow[t]{2}{*}{ Country: $0=$ US, $1=$ Australia } & $0.613^{* * *}$ & $0.961^{* *}$ & $0.446^{*}$ & $0.977^{* * *}$ \\
\hline & $(0.236)$ & $(0.424)$ & $(0.251)$ & $(0.314)$ \\
\hline \multirow{2}{*}{$\begin{array}{l}\text { (Trust in the home country) } X \\
\text { subgroup }\end{array}$} & 0.158 & 0.0327 & -0.326 & $0.511^{* *}$ \\
\hline & $(0.254)$ & $(0.272)$ & $(0.256)$ & $(0.260)$ \\
\hline \multirow{2}{*}{$\begin{array}{l}\text { (Australia } X \text { trust in the home } \\
\text { country) } X \text { subgroup }\end{array}$} & 0.407 & 0.0954 & 0.129 & $-0.727^{* *}$ \\
\hline & $(0.319)$ & $(0.362)$ & $(0.328)$ & $(0.335)$ \\
\hline \multirow{2}{*}{$\begin{array}{l}\text { (Country: } 0=U S, 1=\text { Australia) } X \\
\text { subgroup }\end{array}$} & 0.124 & -1.052 & 0.367 & -0.235 \\
\hline & $(0.348)$ & $(0.728)$ & $(0.352)$ & $(0.352)$ \\
\hline R-squared & 0.127 & 0.133 & 0.127 & 0.127 \\
\hline Observations & 9,793 & 9,793 & 9,793 & 9,793 \\
\hline
\end{tabular}

Subgroups: Male individuals; individuals older than 45 years old; individuals with two parents born abroad; individuals belonging to large migrant communities.

Levels of significance: *: $10 \%$ **: $5 \%$ ***: $1 \%$.

Sample: second-generation immigrants residing in the United States or in Australia.

Note: standard errors (clustered at the individual level) in parentheses. The additional controls are as in Table 2, column 3.

Source: HILDA 2005, 2006, 2008, 2010 and GSS 1978-2010.

Dependent variable: Most people can be trusted (0: No; 1: Yes).

the characteristics inherited from their parents and thus from their home country. However, the results do not suggest any major age-related differences in either of the two countries.

For Australia and the United States, the impact of the average trust in the home country appears to be smaller when both parents were born abroad. A possible explanation for this fact is that in families in which one parent is native, parents may put more effort in transmitting a foreign heritage in an attempt to 'compensate' for the constant exposure of their children to the culture of the native parent. Conversely, in families in which both parents were born abroad in different countries, two different cultures are transmitted, possibly reducing the effect of a particular home country. Table 1 shows that in Australia when both parents were born abroad they are more often from the same origin, suggesting that the first explanation may prevail. In the United States, however, they are more often from diverse heritages suggesting that the transmission effects are split between two foreign cultures.

Finally, the proportion of immigrants from the same origin in the respondent's host country alters the way in which home-country trust is transmitted to secondgeneration immigrants. In the United States, trust of the home country affects individual trust only in larger communities (0.511). Home-country trust has no effect on the trust level of those immigrants coming from smaller communities, namely those communities ranked in the lowest quartile of the community size distribution in each host country (the estimated effect is only equal to 0.028). However, in Australia, trust is 
transmitted to second-generation immigrants independently of the size of the community ( 0.211 and 0.427 respectively in large and small communities).

Turning to the effect of the host-country dummy, the results suggest that unexplained differences between trust levels of immigrants to the United States and Australia are larger for individuals who are younger than 45 years, have both parents born abroad, and who belong to smaller foreign communities. Since the differences in origins are controlled for, these large differences in trust could come from a stronger process of acculturation to the host country for these subpopulations.

\section{Cultural assimilation: what characteristics of the host country matter?}

Trust levels of second-generation immigrants differ widely between the United States and Australia. To analyse how individual trust varies in time with trust in their host country, we follow Aleksynska (2011) and add to our regressions the average value of trust in the host country in each year of observation (calculated from GSS's and HILDA's full samples). We also interact this new variable with the dummy which identifies the host country (taking the value of 1 for Australia). The coefficient of the interaction term provides us with the differential effect of this correlation in Australia.

We performed this exercise on both the most parsimonious specification proposed in Table 2 (column 1, Additional file 6: Table 12) and the one including all the additional individual and home-country controls (column 2, Additional file 6: Table 12). The introduction of these new variables does not change the relationship between trust in the home country and individual trust. For second-generation immigrants living in the US, a 10 percentage point increase in trust in the home country still relates to an increase in individual trust between 6 and 7 percentage points, depending on the specification. The differential effect for Australia indicates that the link between individual trust and home-country trust is between 5 and 3 percentage points weaker in Australia than in the United States.

The level of trust in the host country is an important predictor of the individual trust level of second-generation immigrants. A 10 percentage point increase in the average trust level in the United States is correlated with an increase in individual trust of similar if not bigger magnitude. The estimated effect is smaller in Australia, but the difference is not statistically significant. When we control for the host-country trust levels, the unexplained difference in individual trust levels between Australia and the United States is still very large. The introduction of the new variables reduces the significance of the estimated effect, but the results still indicate that on average individual trust is 40 to 70 percentage points higher in Australia. This last result suggests that other characteristics of the two countries may also be related to the trust levels of secondgeneration immigrants ${ }^{22}$.

The remainder of this section further explores how differences in the economic and social environments of the United States and Australia could explain the differentials in trust levels of second-generation immigrants. In particular, we analyse the effects of unemployment, segregation by country of origin, crime, economic inequality, perceived racial inequality, growth, female labour force participation, and population density. Using the same specification as in Table 2 column 3, we add controls for these characteristics and an interaction term that captures the differential effect for Australia. More 
precisely, the coefficients of the additional terms give (for the United States and Australia separately) the correlation between the evolution of these characteristics over time and trust.

Because changes in the economic and social environment may not have an immediate influence on trust, we introduce these controls with different lags. In order to smooth the evolution of these characteristics, we use three-year moving averages. For all of the above-mentioned characteristics, we tested 14 different specifications: in one specification, we introduced the current value of each of the variables, while in the other specifications we introduced the lags from the first moving average (based on values from $t$ to $t$-2) up to the 13th moving average (based on values from $t$-12 to $t-14$ ). Table 5 presents the most significant results of this analysis ${ }^{23}$.

The first important result is that in all specifications, trust in the home country remains an important determinant of individual trust. This is in line with the findings of Ljunge (2011) for several European countries and it confirms the strength of the cultural link between second-generation immigrants and their countries of origin. More precisely, the estimated effect for trust in the home country remains stable and is larger in the United States (between 5.6 and 5.8 percentage points for a 10 percentage point increase in trust) than in Australia (the difference with the United States varies between -2.8 and -3.0 percentage points; as before this effect is only marginally significant). This suggests that the characteristics of the environment in the host country do not explain why the intergenerational transmission of trust is more important in the United States. We further investigate this issue in the next section.

The second result is that the environment in the host country influences trust although this effect can appear after a delay of several years. We find only a few significant relationships when including the variables with a one-year lag (unemployment and segregation by home country for Australia, see columns 1 and 2 in Table 5). In this case, the direction of causality remains unclear: an increase in trust can lead to less segregation, but the inverse process may also take place. A number of other characteristics display effects which increase and become significant only if introduced with a minimum lag of 10 years. This is the case for crime rate, economic inequality, and perceived racial inequality (columns 3, 4, and 5 in Table 5 report the results for a 13-year lag). For the link between these variables and individual trust, the direction of causality is less controversial: as the effect of these host-country characteristics is delayed by many years, it appears reasonable to assume that they influence the trust values recorded at the time of the interview. In Australia, second-generation immigrants' trust has increased in relation to distant past reductions in crime and economic inequality, and recent past reduction in segregation by home country and unemployment. In the United States, trust has increased over time in relation to reductions in the perceived level of racial inequality. These results are consistent with the literature that shows negative effects of criminality (Delhey and Newton, 2003), income inequality (Uslaner, 2002), segregation (Alesina and Zhuravskaya, 2011), and perceived racial inequality on trust (Rothstein and Stolle, 2008). Consistently with Leigh (2006), we find that income inequality does not affect coeval trust in Australia. However, we find that its effect does increase with time.

The third result is that some of these host-country characteristics contribute to the differences in trust levels between the United States and Australia. The effects of 
Table 5 OLS regressions, the effect of host-country characteristics

\begin{tabular}{|c|c|c|c|c|c|}
\hline & \multicolumn{5}{|c|}{ 3-year moving averages } \\
\hline & \multicolumn{2}{|c|}{ 1-year lag } & \multicolumn{3}{|c|}{ 13-year lag } \\
\hline & $(1)$ & $(2)$ & (3) & (4) & (5) \\
\hline \multirow[t]{2}{*}{ Trust in the home country } & $0.568^{* * *}$ & $0.568^{* * *}$ & $0.565^{* * *}$ & $0.571^{* * *}$ & $0.576^{* * *}$ \\
\hline & $(0.125)$ & $(0.125)$ & $(0.125)$ & $(0.125)$ & $(0.125)$ \\
\hline \multirow[t]{2}{*}{ Australia $X$ trust in the home country } & $-0.290^{*}$ & $-0.290^{*}$ & $-0.287^{*}$ & $-0.293^{*}$ & $-0.298^{*}$ \\
\hline & $(0.158)$ & $(0.158)$ & $(0.158)$ & $(0.158)$ & $(0.158)$ \\
\hline \multirow[t]{2}{*}{ Country: $0=$ US, $1=$ Australia } & $0.852^{* * *}$ & $2.965^{* * *}$ & $1.311^{* * *}$ & $2.220^{* *}$ & -0.223 \\
\hline & $(0.201)$ & $(0.981)$ & $(0.343)$ & $(1.074)$ & $(0.567)$ \\
\hline \multirow[t]{2}{*}{ Unemployment rate } & -0.001 & & & & \\
\hline & $(0.0103)$ & & & & \\
\hline \multirow[t]{2}{*}{ Australia X unemployment rate } & $-0.041^{*}$ & & & & \\
\hline & $(0.0212)$ & & & & \\
\hline \multirow[t]{2}{*}{ Segregation index } & & -1.039 & & & \\
\hline & & $(1.824)$ & & & \\
\hline \multirow[t]{2}{*}{ Australia $X$ segregation index } & & $-1789.7^{* *}$ & & & \\
\hline & & (703.6) & & & \\
\hline \multirow[t]{2}{*}{ Crime rate } & & & -0.0125 & & \\
\hline & & & $(0.0102)$ & & \\
\hline \multirow[t]{2}{*}{ Australia $X$ crime rate } & & & $-0.191^{* *}$ & & \\
\hline & & & $(0.0759)$ & & \\
\hline \multirow[t]{2}{*}{ Gini coefficient } & & & & 1.291 & \\
\hline & & & & $(2.383)$ & \\
\hline \multirow[t]{2}{*}{ Australia X Gini coefficient } & & & & -5.004 & \\
\hline & & & & $(3.222)$ & \\
\hline \multirow[t]{2}{*}{ Perceived racial inequality } & & & & & $-2.552^{*}$ \\
\hline & & & & & $(1.306)$ \\
\hline \multirow[t]{2}{*}{ Australia X perceived racial inequality } & & & & & $2.202^{*}$ \\
\hline & & & & & $(1.320)$ \\
\hline R-squared & 0.120 & 0.120 & 0.120 & 0.120 & 0.120 \\
\hline Observations & 9,954 & 9,954 & 9,954 & 9,954 & 9,954 \\
\hline
\end{tabular}

Levels of significance: *: $10 \% * *: 5 \% * * *: 1 \%$.

Sample: second-generation immigrants residing in the United States or in Australia.

Note: standard errors (clustered at the individual level) in parentheses. The additional controls are as in Table 2,

column 3.

Source: HILDA 2005, 2006, 2008, 2010 and GSS 1978-2010.

Dependent variable: Most people can be trusted (0: No; 1: Yes).

unemployment, segregation, crime, income inequality, and perceived racial inequality differ significantly between the United States and Australia. This is indicated by the statistical significance of the coefficient of the interaction terms between these variables and the dummy for Australia. Specifically, while unemployment, segregation, crime, and income inequality have a greater negative effect in Australia than in the United States, perceived racial inequality has a smaller negative effect. As a result, the hostcountry dummy mechanically increases in the first case and decreases in the second ${ }^{24}$. For example, if crime rates were 0 per cent in the United States and Australia, the difference in trust between the two countries would be much greater (1.311). The coefficient on the host-country dummy has increased (compared with the case of no 
controls) because when reducing crime rates to 0 , trust increases especially in Australia, widening the gap between the two countries.

One interesting exercise is to calculate the values that these host-country characteristics would need to take to eliminate the difference in trust between the two countries. Since crime rates have a negative effect only in Australia, an increase in crime would reduce trust in Australia and lead to a reduction in the difference in trust between the two countries 13 years later. This difference would be cancelled out for a crime rate of 7 per cent (instead of the current rate 3.8 per cent Australia is facing) ${ }^{25}$. Similarly, since past income inequality has a negative effect in Australia, higher values of income inequality would decrease trust and reduce the difference in trust between the two countries. Specifically, a Gini coefficient of 0.48 (instead of the current 0.30) would lower Australia's trust to the US level (13 years later at least). Given its negative effect on trust, a rise in Australia's unemployment rate to 20 per cent (instead of its current 5.1 per cent) would, one year later, lower trust in Australia to the US level. Finally, the difference in trust between the United States and Australia would disappear with a homecountry index of segregation of 0.0017 in Australia (instead of 0.0013). In the United States, only a reduction in perceived racial inequality would have an effect which would be large enough to cancel out the difference in trust with Australia. Specifically, trust in the United States would be as high as in Australia if only 15 per cent of secondgeneration immigrants in the United States thought that race matters to get ahead (instead of the current 40 per cent, as recorded by the WVS $)^{26}$.

In all, the low levels of unemployment, segregation by home country, crime, and income inequality partly account for the high level of trust in Australia, and the high perception of racial inequality contributes to the lower levels of trust in the United States. However, these features do not explain the differences in the intergenerational transmission of trust between the United States and Australia.

\section{Intergenerational transmission: evidence on first-generation immigrants}

We showed in Section 5 that our results are robust to the inclusion of a large set of individual, country and local controls, and to the use of alternative samples and specifications. The differences observed in the transmission of trust to second-generation immigrants in the United States and Australia could still conceal an effect of endogenous migration. This could happen if, by host country, either immigrants themselves or their countries of origin differ in terms of trust. In this section we focus on these selection effects and perform some additional tests to assess their relevance with respect to our estimates.

\subsection{Endogenous migration in relation to trust in the home country}

It is possible that immigrants from certain countries select into specific destinations so that their trust would be spuriously correlated with the average trust in their host country. Specifically, if individuals from countries with high average levels of trust tend to migrate to other countries with high levels of trust, the effects of culture and environment could not be disentangled. The descriptive evidence presented in Figure 1-showing that trust levels of second-generation immigrants exhibit a fair amount of variation by home country in both host countries-suggests this type of selection may not be too relevant. To assess this issue more precisely, we tested whether countries whose emigrants moved to the 
United States differ in terms of average trust from those whose emigrants moved to Australia. We regress the average level of trust in the countries of origin on the average trust in the host country (either the United States, Australia, or both). Results are reported in Additional file 7: Table 13. Whether we use the first wave of the WVS or all waves available, results show no correlation between the level of trust in home and host countries. This suggests that immigrants who move to the United States and Australia come from countries with similar levels of trust.

\subsection{Endogenous migration in relation to individual trust}

Endogenous migration may also occur in relation to individual levels of trust. There are at least two possible scenarios. First, immigrants could select in their host country depending on their attachment to the cultural values of their home country: for example, immigrants whose levels of trust is close to the average levels recorded in their home country may systematically migrate to the United States, while those whose trust differs from the average in the home country may migrate to Australia. This would explain why we find that the relationships between trust of immigrants and trust in the home country are stronger in the United States than in Australia. Second, immigrants could self-select into a host country based on their trust level: immigrants with higher levels of trust could migrate to Australia while those with lower levels of trust migrate to the United States, thus creating a spurious correlation between individual trust and the host-country dummy. To test these hypotheses, we regress individual trust of first-generation immigrants on trust in their home country as specified in equation (1), following the same specifications as in Table 2 for second-generation immigrants. Results are presented in Table 6.

Results show that the effect of trust in the home country is similar for the United States and Australia. As soon as individual controls are added to the model (specification 2), the interaction term between trust in the home country and Australia becomes insignificant and very small in magnitude in our baseline specification 3. This suggests that migrants do not move toward the United States instead of Australia because they are initially closer to their home country average levels of trust: they carry over the same degree of trust from their home country. Therefore, the higher effect on secondgeneration immigrants that we found in the United States than in Australia may suggest a larger intergenerational transmission of trust in the United States.

For first-generation immigrants the effect of the host-country dummy is relatively small and its significance decreases as controls are added. This indicates that firstgeneration immigrants do not exhibit unexplained differences in trust by host country that are as large as those we found for second-generation immigrants. They do show differences, but these first-generation immigrants possibly spent a significant part of their life in their host country. This suggests that differences in trust between the United States and Australia are larger for second-generation immigrants than for firstgeneration immigrants, possibly because the trust of second-generation immigrants converges towards the different levels of trust of the two host countries ${ }^{27}$.

\section{Conclusions}

This paper analyses the impacts of cultural transmission and contemporaneous environment on trust. We disentangle the effects of the different factors by focusing on 
Table 6 OLS regressions, first-generation immigrants

\begin{tabular}{lccc}
\hline & $\mathbf{( 1 )}$ & $\mathbf{( 2 )}$ & $\mathbf{( 3 )}$ \\
\hline Trust in the home country & $0.845^{* * *}$ & $0.534^{* * *}$ & $0.313^{* *}$ \\
& $(0.106)$ & $(0.120)$ & $(0.157)$ \\
Australia X trust in the home country & $-0.471^{* * *}$ & -0.104 & 0.064 \\
& $(0.129)$ & $(0.140)$ & $(0.183)$ \\
Country: $0=$ US, 1 = Australia & $0.462^{* * *}$ & $0.398^{* *}$ & $0.371^{*}$ \\
R-squared & $(0.119)$ & $(0.172)$ & $(0.203)$ \\
Observations & 0.099 & 0.139 & 0.140 \\
Time fixed effects & 8,226 & 8,226 & 8,226 \\
Age and age squared & Yes & Yes & Yes \\
Other individual controls & Yes & Yes & Yes \\
Home-country characteristics & No & Yes & Yes \\
\hline
\end{tabular}

Levels of significance: *: $10 \% * *: 5 \% * * *: 1 \%$.

Sample: first-generation immigrants residing in the United States or in Australia. Note: standard errors (clustered at the individual level) in parentheses. The additional controls are as in Table 2.

Source: HILDA 2005, 2006, 2008, 2010 and GSS 1978-2010.

Dependent variable: Most people can be trusted (0: No; 1: Yes).

second-generation immigrants who live in two different countries: the United States and Australia.

Our results clearly indicate that both the home country and the host country matter. Specifically, cultural transmission is particularly important in explaining trust levels in the United States, although a positive relationship between trust in the home country and individual trust can also be detected in Australia. This finding confirms the claim made by Uslaner (2008) that "trust/social capital follows the flag in the American melting pot" ${ }^{28}$. Further, large differences appear in trust levels between the two host countries, thus suggesting that the environment matters as well. These results are robust to including a large set of controls (individual, home-country, and regional characteristics in the host country), and different samples and different econometric specifications.

Interestingly, differences in levels and in the transmission of trust across generations between the United States and Australia are not homogenous in the population. In particular, in Australia women's trust is not affected by trust in their home country, however it is for men. In contrast, in the United States women's trust is as affected by their origin in the same way it is for men. The transmission of this foreign heritage appears particularly strong when only one parent was born abroad. Finally, trust in the home country has no effect on the trust of individuals belonging to small communities in the United States.

While the literature has mainly focused on the impact of cultural background, we extend the analysis to the effect of economic and social conditions of the host country on trust. Low levels of unemployment, segregation by home country, crime, and income inequality partly account for the high level of trust in Australia, and the perception of racial inequality contributes to lower levels of trust in the United States. This result has important policy implications, as modifications of these characteristics may impact on the average levels of trust of second-generation immigrants.

To expand our understanding of the differences in the transmission process of trust between the United States and Australia, we reproduce our main analysis for firstgeneration of immigrants. Results show that, for them, the influence of the home 
country is similar in both the United States and Australia. This suggests that immigrants arrive in their host country carrying the same degree of trust from their home country. Furthermore, results show smaller differences in first-generation immigrants' trust levels by host country. This strengthens our findings that the transmission process is larger in the United States, and that the difference in trust levels of immigrants increases with time as a result of an acculturation process.

The evidence provided in this paper showing that culture and environment matter for second-generation immigrants opens interesting perspectives for future research. Notably, the question of whether our findings are valid for other behavioural traits may provide us with a better understanding of how migrants build a mixed identity between the host country and the home country.

\section{Endnotes}

${ }^{1}$ See, among others, Guiso et al. (2004), Algan and Cahuc (2007a), Algan and Cahuc (2010), Horváth (2013) and Sangnier (2013).

2 In the economics literature, 'culture' refers to the social preferences and beliefs that characterise a social group and are transferred from generation to generation. Consistently, we use the term 'culture' or 'cultural background' to refer to the immigrants' home country. Variation in immigrants' culture is used to estimate the importance of intergenerational transmission. See Fernandez (2011).

3 This approach has been used to study the effect of culture on a variety of outcomes, including savings (Carroll et al. 1994); women's work and fertility (Fernandez and Fogli 2009; Blau et al. 2011); political attitudes (Alesina and Giuliano 2011); preferences for redistribution (Luttmer and Singhal 2011) among others.

${ }^{4}$ We use trust levels rather than country of origin dummies to capture how much immigrants' trust was inherited from their country of origin (not simply how trust levels of immigrants differ by origin). This method is supported by Fernandez (2011) who argues that 'although it is possible to simply use a country-of-ancestry dummy for this variable, a superior strategy is to use a variable that more directly reflects the cultural attitudes of interest'. In this paper, we use the exact variable for trust beliefs in the country of origin rather than a proxy. This reduces the risk of biasing our estimates by capturing other differences in the countries of origin. Furthermore, this enables us to introduce controls at the country-of-origin level to test for the influence of possible confounding factors in the transmission of trust.

${ }^{5}$ We also test a version of the model which includes region of residence controls (GDP growth, unemployment rate, density of population, crime rate) and the percentage of immigrants from the same home country in each host country. The region of residence corresponds to the State or Territory of residence in Australia (Australian Capital Territory; New South Wales; Northern Territory; Queensland; South Australia; Tasmania; Victoria) and to the Census region of residence for the United States (New England; Middle Atlantic; East North Central; West North Central; South Atlantic; East South Central; West South Central; Mountain; Pacific). The use of Census regions instead of States is due to the impossibility for the authors to access the confidential version of the GSS data.

${ }^{6}$ A different approach is to introduce yearly fixed effects for all years but one. Doing so yields similar results: estimates in Additional file 4: Table 10 column 1 are very 
similar to our main specification (Table 2, column 3). We provide additional checks in the robustness section by keeping only the years 2000s or removing 2005; these changes do not alter our results.

${ }^{7}$ Our index of segregation follows Alesina and Zhuravskaya (2011). It uses the regional composition by countries of origin to build an index which equals 1 if each region comprises only immigrants with one country of birth (full segregation) and zero if each region has the same fraction of each country of birth (no segregation). We use

their approach which ignores the group of 'other' countries of birth: $\tilde{S}=\frac{1}{N-1}$ $\sum_{m=1}^{N} \sum_{j=1}^{J} \frac{t_{j}}{T} \frac{\left(\pi_{j m}-\pi_{m}\right)^{2}}{\pi_{m}}$ where $T$ is the total population of the country, $t_{j}$ is the population of region $j, J$ is the total number of regions, $N$ is the total number of groups, $\pi_{m}$ is the fraction of people born in country $m$, and $\pi_{j m}$ is the fraction of people born in country $m$ in region $j$.

${ }^{8}$ However, to ensure a large enough sample for the United States, using data for the whole period is necessary.

${ }^{9}$ We use this comprehensive definition for immigrant status to retain as many observations as possible. We thus expect to obtain a lower bound for the effect of the country of origin, since some individuals in our sample have been confronted to different cultures from their parents. We provide evidence in the results section that taking the mothers' country of birth instead does not alter the results (this changes the origin of individuals who have both parents born abroad in different countries: 8 per cent in HILDA and 39 per cent in GSS).

${ }^{10}$ Lebanon, Sri Lanka and Papua New Guinea are dropped from the HILDA sample, since no data are available for these countries in the WVS. This leads to a loss of 87, 57, and 49 observations respectively. In line with Uslaner (2002) and Müller et al. (2012), we drop China (for which the level of trust reported in the WVS appears suspiciously high).

${ }^{11}$ We check that taking the average over all WVS waves containing the trust question or alternatively taking the last value before our individuals are born (which only changes the value for 4 per cent of the people) does not significantly alter the results (see Additional file 5: Table 11. Results are discussed in section 6). We prefer to take the first value, which is obviously the closest to the immigration date. Under the assumption that trust is strongly embodied in countries and does not evolve erratically, it is possible to use future values for the cultural variable with respect to the outcome. That is, we can explain individual trust by subsequent trust in the country of origin. Fernandez (2007) demonstrates that using past or future cultural variables yields similar results in the case of female labour force participation. Of course, the bias due to this systematic measurement error cannot be eliminated.

${ }^{12}$ For these variables, we were able to gather data with the required time variation. The data we found on religion from the WVS (Uslaner 2002), social mobility from the WVS (Rothstein and Uslaner 2005), regulations and demand for regulation from the ISSP (Aghion et al. 2010) and civic mindedness from the WVS (Aghion et al. 2010) were not showing enough time variation to enable us to use them for Australia in the analysis, as Australia is only studied from 2005 to 2010. 
13 This variable takes the following values: 1 "Essential"; 2 "Very important"; 3 "Fairly important"; 4 "Not very important"; 5 "Not important at all". We group the first three values: 'fairly important' to 'essential' and calculate the proportion who think that race is important to get ahead in each country at each survey wave (1987, 1992, and 2009). We then use linear approximations to calculate values for each year covered by the GSS and HILDA. For GSS and HILDA waves occurring before the first value is available, we take the first value available (which is only the case for the GSS before 1987); if the survey year is after the last value in the ISSP, we take the last ISSP value available (that is HILDA and GSS 2010).

14 The number of lags employed in this analysis is driven by data availability. The GSS data we use in the paper start in 1978. For most of the US variables, the first year of observation is 1965 , so a 14 year lag is the longest lag we can include in the analysis.

15 Average values from GSS (1978-2010) and HILDA (2005-2010).

${ }^{16}$ Results are available from the authors on request.

17 Trust in home countries varies between 0.06 and 0.61 , with a standard deviation of 0.12 in the United States and between 0.055 and 0.49 with a standard deviation of 0.09 in Australia. See Table 1.

${ }^{18}$ As the information for trust in the country of origin given by the WVS is fairly recent, the older the individuals the less precise is our proxy for trust in the country of origin at the time of migration. To control for this potential bias, we included the difference between the year of birth of the respondents and the year in which we have the first information for trust in the country of origin (in the WVS). This variable did not have any significant effect on trust, and the other coefficients do not vary significantly when this new variable is introduced to the set of regressors.

19 The simultaneous introduction of the regional controls and of the country-level characteristics is not possible due to multicollinearity issues, driven by low levels of variation in the Australian variables. To preserve the possibility to compare the results presented in Table 2 with those presented in Table 5, the regional controls are not included in our main specification. We study the effect of these (and other) characteristics at the hostcountry level in the next section. We have also tested the inclusion of two additional controls: the distance between the capital of the home country and that of the host country so as to control for geographic proximity and the female to male labour force participation ratio in the home country. Results are absolutely similar and are available from the authors on request. We chose not to include these controls in our main specification because they may be endogenous. First, individuals willing to escape from their home country (for example in time of war) possibly tend to migrate further away and come from low-trusting countries. If we control for distance, the coefficient on trust in the home country would become insignificant, even in the presence of intergenerational transmission. Second, if there is a relationship between trust and the female to male labour force participation ratio, the direction of causality is unclear. It could very well be that trusting values are transmitted and then translate into similar behaviours across generations, such that the effect of trust in the home country could vanish, even if trust is transmitted across generations.

${ }^{20}$ We also repeated the analysis dropping the former communist countries. As the results are largely in line with those already presented, we do not report them here. They can be made available by the authors upon request. 
${ }^{21}$ In the second case, standard errors are clustered at the home-country level instead of the individual level.

${ }^{22}$ In the remainder of the paper, we use the empirical specification adopted in the previous section (Table 2, column 3), i.e. without time-varying controls for trust at the host-country level. The Australian data covers a very limited interval of time. As trust tends to be quite constant overtime, we cannot introduce several host-country characteristics simultaneously in our specification.

${ }^{23}$ All the results are not shown here (other lags and other variables) are available from the authors upon request.

${ }^{24}$ Note that the interpretation of the country dummy is slightly different from that of the previous sections. It now gives the difference in trust between the United States and Australia if the values of host-country characteristics included in the regression were equal to 0 .

${ }^{25}$ This is the value of crime rate $x$ such that: $1.311+0.0125 * 8.58+(-0.0125-0.191) x=0$.

${ }^{26}$ We have analysed the effects of GDP growth, population density, and female labour market participation. Even if some of these characteristics are significantly related to trust, their effect is too small to foster trust in the United States meaningfully or to lower trust in Australia. For example, it would require a 46 per cent GDP growth rate in the United States in order to increase trust up to the Australian level.

27 This test is obviously imperfect, since the sample of first generation immigrants does not include the parents of the second-generation immigrants. They are thus from different countries and different immigration waves. To mitigate this issue, we restricted the first generation sample to home countries which are represented in the sample of second-generation immigrants. Yet, this could explain the smaller main impact of trust in the country of origin.

${ }^{28}$ Uslaner (2008), p. 730.

\section{Additional files}

Additional file 1: Table 7. Countries of origin in each dataset.

Additional file 2: Table 8. Variable harmonization across GSS and HILDA datasets.

Additional file 3: Table 9. OLS regressions. Dependent variable: Most people can be trusted (0: No; 1: Yes).

Additional file 4: Table 10. Robustness checks. Different econometric methodologies. Dependent variable: Most people can be trusted (0: No; 1: Yes).

Additional file 5: Table 11. Additional robustness checks. Dependent variable: Most people can be trusted (0: No; 1: Yes).

Additional file 6: Table 12. Robustness checks. Regressions with augmented sets of regressors. Dependent variable: Most people can be trusted (0: No; 1: Yes).

Additional file 7: Table 13. OLS regressions. Relationship between trust in home countries and host countries

The IZA Journal of Migration is committed to the IZA Guiding Principles of Research Integrity. The authors declare that they have observed these principles.

\section{Acknowledgments}

For their helpful comments and suggestions we thank Pierre Cahuc, Deborah Cobb-Clark, Giovanna Labartino, Patrick Nolen, Marc Sangnier, Eric Uslaner, and the participants at the EALE Conference in Bonn, the AFSE Conference in Paris, the AIEL Conference in Napoli, the fRDB Fellows and Affiliates Workshop in Milan, the ESAM Conference in Melbourne and the seminars at the Melbourne Institute, University of Surrey and Queen's University Belfast. We thank the editor and an anonymous referee for their extremely useful comments on an earlier version of the paper. This paper was supported by a 2012 Faculty Research Grant (Early Career Researcher Category) of the Faculty of Business and Economics of the University of Melbourne. This paper uses unit record data from the Household, Income and Labour Dynamics in Australia (HILDA) Survey. The HILDA Project was initiated and is funded by the Australian Government 
Department of Social Services (DSS) and is managed by the Melbourne Institute of Applied Economic and Social Research (Melbourne Institute). The findings and views reported in this paper, however, are those of the author and should not be attributed to either DSS or the Melbourne Institute.

Responsible editor: Corrado Giulietti

\section{Author details}

'Melbourne Institute of Applied Economic and Social Research, The University of Melbourne, 1-100 Grattan Street, Parkville, VIC 3010, Australia. ${ }^{2}$ Université Paris-Ouest Nanterre, Nanterre, Cedex 92001, France. ${ }^{3}$ Université de Genève, Uni Mail, 40, bd du Pont-d'Arve, 1211, Genève 4, Switzerland. ${ }^{4}$ NCCR LIVES, Genève, Switzerland. ${ }^{5}$ Institute for the Study of Labor (IZA), Bonn 53113, Germany.

\section{Received: 8 January 2014 Accepted: 8 May 2014}

Published: 30 May 2014

\section{References}

Aghion P, Algan Y, Cahuc P, Shleifer A (2010) Regulation and distrust. Q J Econ 125(3):1015-1049

Aleksynska M (2011) Civic participation of immigrants in Europe: Assimilation, origin and destination country effects. Eur J Polit Econ 27:566-585

Alesina A, Giuliano P (2011) Family ties and political participation. J Eur Econ Assoc 9(5):817-839

Alesina A, Zhuravskaya $E$ (2011) Segregation and the quality of government in a cross section of countries. Am Econ Rev 101(5):1872-1911

Algan Y, Cahuc P (2007a) The roots of low European employment: Family culture? In: Pissarides C, Frankel JA (eds) NBER International Macroeconomics Annual. MIT Press, Cambridge, pp 65-109

Algan Y, Cahuc P (2007b) La société de défiance: comment le modèle social français s'autodétruit: Edition de la rue d'Ulm, Collection du Cepremap

Algan Y, Cahuc P (2010) Inherited trust and growth. Am Econ Rev 100(5):2060-2092

Algan Y, Cahuc P, Sangnier M (2011) Efficient and Inefficient Welfare States. IZA Discussion Papers 5445. Institute for the Study of Labor (IZA),

Arrow K (1972) Gifts and exchanges. Philosophy and Public Affairs 1:343-362

Bisin A, Verdier T (2001) The economics of cultural transmission and the evolution of preferences. J Econ Theory 97 (2):298-319

Blau F, Kahn L, Papps K (2011) Gender, source country characteristics and labor market assimilation among immigrants. Review of Economics and Statistics 93(1):43-58

Carroll CD, Rhee C, Rhee B (1994) Are there cultural effects on saving? Some cross-sectional evidence. Q J Econ 109 (3):685-700

Delhey J, Newton K (2003) Who trusts? The origins of social trust in seven societies. Eur Soc 5(2):93-127

Dinesen PT (2011) Where you come from or where you live? Examining the cultural and institutional explanation of generalized trust using migration as a natural experiment. Eur Sociol Rev 29(1):114-128

Dinesen PT (2012a) Parental transmission of trust or perception of institutional fairness: Generalized trust of non-Western immigrants in a high-trust society. Comparative Politics 44(3):273-289

Dinesen PT (2012b) Does generalized (dis)trust travel? Examining the impact of cultural heritage and destination-country environment on trust of immigrants. Political Psychology 20(20):1-17

Dinesen PT, Hooghe M (2010) When in Rome, do as the Romans do: The acculturation of generalized trust among immigrants in Western Europe. Int Migr Rev 44(3):697-727

Dohmen T, Falk A, Huffman D, Sunde U (2012) The intergenerational transmission of risk and trust attitudes. Review of Economic Studies 79(2):645-677

Fehr E, Fischbacher U, Schupp J, von Rosenbladt B, Wagner GG (2003) A Nationwide Laboratory Examining Trust and Trustworthiness by Integrating Behavioural Experiments into Representative Surveys. CEPR Discussion Papers 3858

Fernandez R (2007) Women, work and culture. J Eur Econ Assoc 5(2-3):305-332

Fernandez R, Fogli A (2009) Culture: An empirical investigation of beliefs, work and fertility. American Economic Journal: Macroeconomics 1(1):146-177

Fernandez R (2011) Does Culture Matter? In: Benhabib J, Jackson MO, Bisin A (eds) Handbook of Social Economics, Vol. 1A, Amsterdam: North-Holland, pp 481-510

Glaeser E, Laibson D, Sheinkman J, Soutter C (2000) Measuring trust. Q J Econ 115(3):811-846

Glaeser E (2005) The political economy of hatred. Q J Econ 120(1):45-86

Guiso L, Sapienza P, Zingales L (2004) The role of social capital in financial development. Am Econ Rev 94(3):526-556

Guiso L, Sapienza P, Zingales L (2006) Does culture affect economic outcome? J Econ Perspect 20(2):23-48

Horváth R (2013) Does trust promote growth? J Comp Econ 41(3):777-788

Knack S, Keefer P (1997) Does social capital have an economic payoff? A cross-country comparison. Q J Econ 112 (4):1251-1288

La Porta R, Lopez-de-Silanes F, Shleifer A, Vishny R (1997) Trust in large organizations. Am Econ Rev 87(3):333-338

Leigh A (2006) Trust, inequality and ethnic heterogeneity. Economic Record 82(258):268-280

Ljunge M (2011) Trust Issues: Evidence from Second Generation Immigrants. University of Copenhagen, Department of Economics Discussion Paper, pp 11-31

Ljunge M (2012) Cultural transmission of civicness. Econ Lett 117:291-294

Luttmer E, Singhal M (2011) Culture, context, and the taste for redistribution. American Economic Journal: Economic Policy 3(1):157-179

Müller D, Torgler B, Uslaner EM (2012) A comment on 'inherited trust and growth'. Econ Bull 32(2):1481-1488

Rothstein B, Stolle D (2008) The state and social capital: An institutional theory of generalized trust. Comparative Politics 40(4):441-459 
Rothstein B, Uslaner EM (2005) All for all: Equality, corruption and social trust. World Politics 58(1):41-72

Sangnier M (2013) Does trust favor macroeconomic stability? J Comp Econ 41(3):653-668

Smith TW, Marsden P, Hout M, Kim J (2011) General social surveys, 1972-2010[machine-readable data file]/Principal Investigator, Smith, T.W. Co-Principal Investigator, Marsden P.V.; Co-Principal Investigator, Hout, M.. Sponsored by National Science Foundation. In: NORC (ed). National Opinion Research Centre [producer]; Storrs, CT: The Roper Centre for Public Opinion Research, University of Connecticut [distributor], Chicago

Tabellini G (2008) Presidential address: Institutions and culture. The Journal of the European Economic Association 6(2-3):255-294

Tabellini G (2010) Culture and institutions: Economic development in the regions of Europe. J Eur Econ Assoc 8(4):677-716

Thöni C, Tyran J-R, Wengström E (2012) Microfoundations of social capital. J Public Econ 96(7-8):635-643

Uslaner EM (2002) The Moral Foundations of Trust. The Cambridge University Press, Cambridge

Uslaner EM (2008) Where you stand depends upon where your grandparents sat: The inheritability of generalized trust Public Opinion Quarterly 72(4):725-740

Uslaner EM (2011) Trust, diversity, and segregation in the United States and the United Kingdom. Comp Sociol 10 (2):221-247

Williamson OE (1979) Transactions-cost economics: The governance of contractual relations. J Law Econ 22(2):233-262

World Values Survey Association (2009) World Values Survey 1981-2008 Official Aggregate v.20090901. Aggregate File Producer, ASEP/JDS, Madrid, www.worldvaluessurvey.org

doi:10.1186/2193-9039-3-10

Cite this article as: Moschion and Tabasso: Trust of second-generation immigrants: intergenerational transmission or cultural assimilation? IZA Journal of Migration 2014 3:10.

Submit your manuscript to a SpringerOpen ${ }^{\circ}$ journal and benefit from:

- Convenient online submission

- Rigorous peer review

- Immediate publication on acceptance

- Open access: articles freely available online

- High visibility within the field

- Retaining the copyright to your article

Submit your next manuscript at $\gg$ springeropen.com 


\section{University Library}

\section{- M M I E E R VA A gateway to Melbourne's research publications}

Minerva Access is the Institutional Repository of The University of Melbourne

Author/s:

MOSCHION, J;Tabasso, D

Title:

Trust of second-generation immigrants: intergenerational transmission or cultural assimilation?

Date:

2014

Citation:

MOSCHION, J. \& Tabasso, D. (2014). Trust of second-generation immigrants:

intergenerational transmission or cultural assimilation?. IZA Journal of Migration, 3 (1), https://doi.org/10.1186/2193-9039-3-10.

Persistent Link:

http://hdl.handle.net/11343/124189 